\title{
Vom Schlachten heiliger Kühe
}

\author{
Ch. Schubert (Text), S. Bobbià (Illustration)
}

Pfui, welch ein Frevel!

Tierschützer, Hinduisten, BSE-Freunde und Pazifisten, auf die Barrikaden! Da reitet einer eine Attacke gegen die guten Sitten! «Schlachten», das ist doch ein Aufruf zur Gewalt; "heilig» schreit ja förmlich nach Sakrileg; und die Kühe lasse man gefälligst in Ruhe, die armen Tiere.

Aber halt! Es ist doch bloss eine Satire.

Satire?

Satire: "An keine bestimmte literarische Form gebundene Gattung, die in geistreicher Sprache Torheiten und Laster verhöhnt, missbilligende Kritik übt und oft in Gestalt von Roman, Gedicht oder auch Drama auftritt [...].» [1]

Da befinden wir uns ja in bester Gesellschaft, denn die Liste der Satiriker ist lange: Horaz, Juvenal, Voltaire, Rabelais, Defoe, Lessing, Goethe, Schiller, Heine, Mann, Böll, Kästner, Morgenstern, Dürrenmatt, Frisch, Bichsel, Shaw, Monty Python, ...

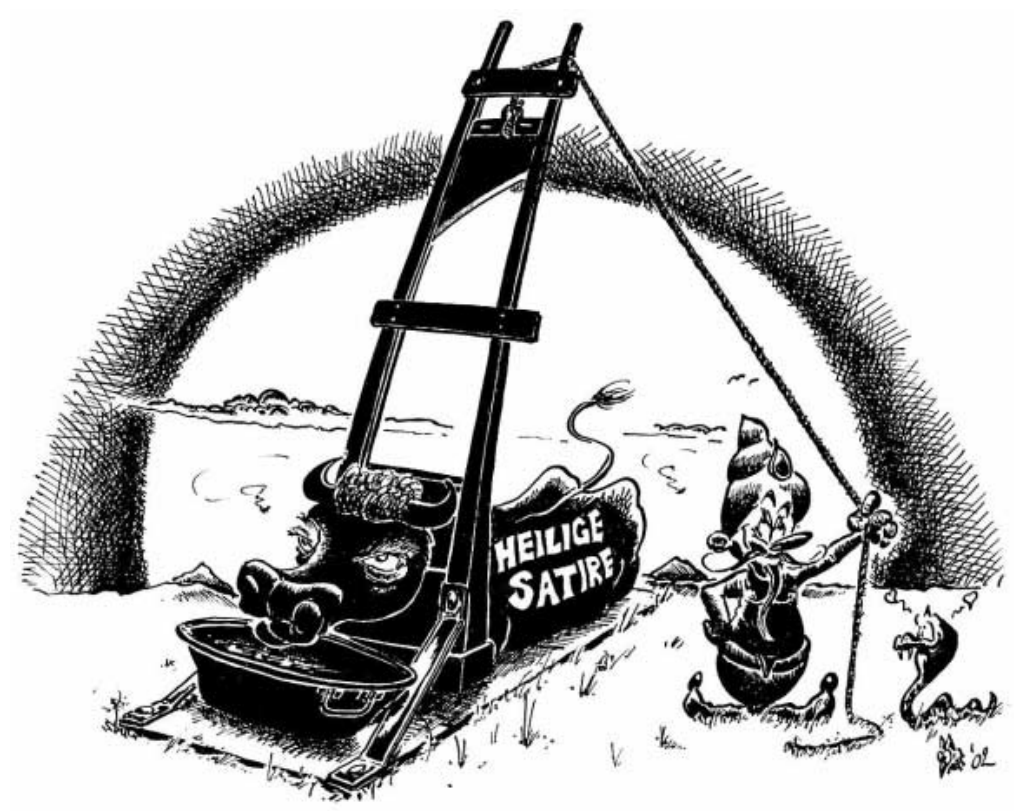

Korrespondenz:

Dr. med. Christoph Schubert

Weissenrainstrasse 44

CH-8707 Uetikon am See

E-Mail: schubert@schubertrufener.com
So weit, so gut. Warum aber kann jemand überhaupt auf die Idee kommen, eine Satire zu schreiben? Kurt Tucholsky war nicht um eine Antwort verlegen: «Der Satiriker ist ein gekränkter Idealist: er will die Welt gut haben, sie ist schlecht, und nun rennt er gegen das Schlechte an.» [2].

Ein Veränderer ist er also, der Satiriker, ein Progressiver, oder zumindest einer, der einen Fortschritt herbeisehnt, und damit zwangsläufig ein unerbittlicher Gegner des Konservativismus. Und schon sitzen wir mitten im trauten Heim des keifenden alten Ehepaares, das da heisst "Sesshaftigkeit» und "Fortschritt». Sie gehören zusammen, die beiden, denn sie wohnen in jedes Menschen Brust und zanken fortwährend, und doch kann keiner ohne den andern sein. Die Sesshaftigkeit ist das Wurzelwerk, mit dem wir uns am Steilhang des Seins festkrallen, und am Fortschritt kommen wir eh nicht vorbei: Fortschritt ist nötig, da er ohnehin stattfindet. Aber Fortschritt bedeutet Veränderung, und jede Veränderung beinhaltet ein Verlassen von Bekanntem, und das kann wehtun, besonders wenn das Bekannte angenehm war.

Der Mensch braucht also einen Tritt in den Hintern, um zum Verlassen seines Pfuhls der Lethargie bewegt zu werden: «Die Satire muss übertreiben und ist ihrem tiefsten Wesen nach ungerecht. Sie bläst die Wahrheit auf, damit sie deutlicher wird, [...].» [2].

Tucholskys Aufsatz trägt den Titel "Was darf Satire?» und gibt auch gleich die vielzitierte Antwort: "Alles!"

Darf die Satire wirklich alles?

Ja, sie darf; sie muss es dürfen, um ihren Zweck zu erfüllen, nämlich Veränderungen herbeizurufen. Kein Aspekt unseres Daseins bleibt vor Veränderungen verschont, somit darf es auch für die Satire kein Tabu geben, wie es auch für die Meinungsfreiheit kein Tabu geben darf, und für die Schreibenden keine Zensur.

Satire ist eine Form von Humor.

Humor?

Humor: «Heitere Gelassenheit gegenüber den Unzulänglichkeiten von Welt und Menschen und den Schwierigkeiten des Alltags [...].» [3].

Die Allgemeingültigkeit der Definition schreit nach Präzisierung, und der Schrei bleibt nicht ungehört. Eine Fülle von Erklärungsversuchen, Abhandlungen und Diskussionen findet sich in Literatur und Forschung [4]. Sicher ist, dass der Humor viele Facetten hat, und jeder Mensch seinen eigenen Humor [5]. Genausowenig wie Anästhesisten und Chirurgen, PC und Mac oder Cubeheads und Coneheads kompatibel sind, ist von den verschiedenen Ausprägungen des Humors zu erwarten, dass sie alle unter einem Hut Platz finden. Was den einen zum Lachen bringt, mag ein anderer pietätlos finden und lässt einen dritten gänzlich unberührt. Wie viele Ostfriesen lachen über Ostfriesenwitze? Und was sagen die Blondinen dazu? 
Guter Geschmack, werden Sie sagen, es ist alles nur eine Frage des guten Geschmacks. Davon kann jeder Koch ein Liedchen singen: dem einen Gast ist's $\mathrm{zu}$ scharf, dem andern zu fade und der dritte isst grundsätzlich nichts ohne Puderzucker. Der gute Geschmack ist nicht einmal eine Frage der feinen Linie zwischen bitter und süss, sondern ein Wald mit vielen Bäumen, wo jeder sein Schattenplätzchen finden kann - halt nicht alle unter dem gleichen Baum.

Es kann also nicht das Ziel sein, einen allgemein verträglichen Humor zu schaffen, sondern es gilt den eigenen Humor zu entwickeln, auszuweiten und gleichzeitig zu schärfen, und ihn so zu einer möglichst authentischen Eigenschaft zu machen, deren Stimmigkeit vom Gegenüber wahrgenommen werden kann. So lässt sich - eine humoristische Reife des Gegenübers vorausgesetzt - ein "Einklang der Humore» erzielen, ohne in der wässrigen Seichtheit der Spassgesellschaft herumzudümpeln.

Doch je bissiger die Satire, je pointierter die Aussage und je griffiger der Humor, desto zahlreicher werden die Ecken sein, an die man stösst: nicht jeder Hypertoniker mag Salz in seiner Suppe.

In diesem Sinne ist die Satire wie eine Chilischote - dem einen bekommt sie, dem andern nicht!

\section{Literatur}

1 Knaurs Lexikon der Weltliteratur. München: Knaur; 1992.

2 Kurt Tucholsky. Was darf Satire? 1919.

3 Brockhaus-Enzyklopädie. Mannheim Bibliographisches Institut \& F. A. Brockhaus AG; 1989.

4 www.humor.ch

5 William Fry. Creating Humor. 1999. 